\title{
EDITORIAL
}

\section{Sport in action - simple steps to develop and manage talent}

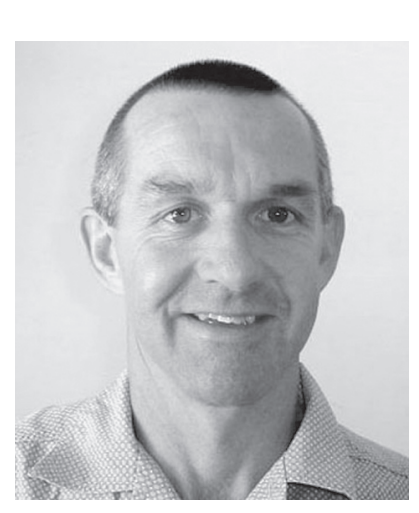

Once again, after the successful hosting of the football World Cup, sport has shown how it can unite a nation, independently of the politicians. As we bask in the afterglow of the World Cup it is worth contemplating how the buzz which was experienced in the country for those four glorious weeks can be maintained. Each time the country has done well in international sport there has been heightened public spirit, which declines with a relatively short half-life. It does not take a sharp mind to realise that if we want to maintain this spirit, which is so important for nation building, we need to improve the level of competitiveness of our top sportsmen and women. We need to be able to compete with the best and win with style and humility. When we lose, we need to do so with grace and courage. Now the hard part - what do we have to change in our current structure to achieve this? Do we have the answers and, most importantly, resources to achieve this?

It was by chance that I came across the findings of a task force which was commissioned by sport and recreation New Zealand (SPARC) (www.sparc.org.nz). The goal of this task force was to compile strategies for talent identification and development in New Zealand. In other words, their goal was to develop a strategy which would improve the sporting competitiveness of the nation. The Talent Development Framework was finalised in 2006. It was developed by a cross-sector task force, the Talent Identification and Development Taskforce, after research into talent identification and development methodologies which existed internationally. Their recommendations were appealing for two reasons: firstly they were simple, realistic and based on common sense, and secondly, if these recommendations are implemented there is a very real chance that the competitiveness of our sports participants on the international level will increase. A summary of the main points of the task force follows (with my comments in italics):

1. Talent is dynamic and multi-dimensional, and cannot be accurately or easily predicted - this is so true and points to the simple fact of letting children play and letting talent emerge naturally. Our responsibility is to create opportunities for play. Specific talent identification programmes are expensive, producing many false positive results.

2. Gifted athletes can emerge at any stage of development - let's change the paradigm of selecting more physically mature chil- dren over children who may mature later. Throwing the selection net wider will most certainly yield a more productive catch.

3. Environment, genetics, mental ability, physiology, and support are all key to developing talent - we all know that, let's just put it into practice.

4. Environment is the easiest element to influence - let's address the imbalance in facilities in the country with as much vigour as was put into building the magnificent stadia for the soccer World Cup, and allow the champions to flourish.

5. Some common attributes of top performing athletes are as follows:

- they were very active as children

- they specialised in one sport later in their development

- they were motivated by the joy of sport rather than winning

- they had access to coaching from an early age.

Schools have an important role in achieving these goals. While some schools are already doing an admirable job, others are hamstrung by a lack of equipment and resources and should be upgraded and supported so that they can offer these minimum requirements for talent development. Let's make coaching a viable career track so that talented coaches can be attracted and supported.

6. Playing a range of sports developed a more advanced skill set for an athlete than concentrating on one sport from an early age let's give physical education its rightful place in the curriculum so that children can be exposed to a range of sports which develop their motor skills and physical ability, laying the foundations for champions.

7. Inhibiting factors were a lack of social and financial support, and fathers who demanded success - the truth lies somewhere between disinterested parents and parents who are too pushy. Parents need to understand their role clearly and provide support without placing too much pressure to perform on the child.

Solutions to problems are sometimes so clear and obvious and for this reason are missed. Reading the New Zealand guidelines gave me confidence that the solution for improving the competitiveness of our sport is right before us and can easily be implemented if we all have the same vision.

\section{Mike Lambert}

Editor-in-Chief 